\title{
EL DEBER DE LEALTAD Y SUS CONCRECIONES EN LA LEGISLACIÓN COOPERATIVA ${ }^{l}$
}

\author{
POR \\ Itziar VILLAFAÑEZ PÉREZ ${ }^{2}$
}

\section{RESUMEN}

Entre los deberes de los miembros de los órganos de gobierno de las diferentes entidades, vinculados al buen gobierno de éstas, destaca el deber de lealtad, derivado del deber de buena fe, y consistente en la obligación de actuar en interés de la entidad en caso de conflicto de intereses con ésta, subordinando los propios a favor de aquélla, salvo que se autorice tal situación. Se trata de un deber predicable tanto respecto de los miembros del órgano de administración, que deben gestionar el interés de la sociedad, como de los socios, tomando en consideración el fin común que deriva del contrato de sociedad. Este deber, al mismo tiempo se concreta en una serie de normas más precisas, relativas a la transparencia, la remuneración, la prohibición de competencia, la autocontratación, etc. Partiendo de lo anterior, este estudio recoge una comparativa de la regulación del deber de lealtad y sus distintas concreciones en las Leyes de cooperativas en España, tanto en relación con los administradores sociales, como de los socios en general, comparando ésta al mismo tiempo con la regulación de estos aspectos en el Derecho de sociedades en general, y en la Ley de Sociedades en General en particular, con el objetivo de obtener una visión general de la cuestión, base necesaria para poder profundizar en ella, planteando una serie de conclusiones o valoraciones preliminares.

Palabras clave: conflictos de intereses, transparencia, buena fe, administradores, socios.

\footnotetext{
${ }^{1}$ Actualización y revisión del trabajo presentado al XV Congreso de investigadores en economía social y cooperativa de CIRIEC-España, celebrado en Santander los días 25 y 26 de septiembre de 2014 ("Concreciones del deber de lealtad en la legislación cooperativa. Estudio comparado").

Elaborado en el marco del proyecto de investigación del Ministerio de Economía y Competitividad "Las obligaciones de transparencia y lealtad de los administradores en las sociedades de capital y en las entidades no lucrativas: un enfoque uniformizador".

${ }_{2}^{2}$ Doctora en Derecho Mercantil. Profesora de Euskal Herriko Unibertsitatea/Universidad del País Vasco. Miembro de GEZKI. Dirección de correo electrónico: itziar.villafanez@ehu.es.

REVESCO No 120 - Primer Cuatrimestre 2016 - ISSN: 1885-8031 - www.ucm.es/info/revesco

http://dx.doi.org/10.5209/rev_REVE.2016.v120.49698
}

Fecha de recepción: 24/09/2014

Fecha de aceptación: 14/05/2015 
Claves ECONLIT: K20, L33, P13, G39, Y10.

\title{
THE DUTY OF LOYALTY IN THE COOPERATIVE LAW. A COMPARATIVE STUDY
}

\begin{abstract}
Among the duties of the government bodies' members of the different entities, which are connected to the good government, the duty of loyalty must be underlined. This duty, derived from the good-faith duty, obliges to act in the interest of the entity in case of conflict of interest, and to subordinate one's own interests, except when there is an authorisation. Loyalty duty is applicable both to managers, who must manage the entity's interest, and to partners, according to the common purpose derived from the company contract. This duty, at the same time, includes some particular rules, referred to transparency, remuneration, prohibition of competition, self-contracting... This essay compares the regulation of the duty of loyalty and its realizations in the different Cooperative Laws in Spain, both referring to the managers and to the partners, comparing this, at the same time, with the regulation of these aspects in companies' general legislation, an in the Spanish Corporate Enterprises Act in particular, in order to obtain a general view of the issue, a necessary basis to go more deeply into it, and suggesting some preliminary conclusions or assessments.
\end{abstract}

Keywords: conflict of interest, transparency, good faith, managers, members.

\section{INTRODUCCIÓN: EL DEBER DE LEALTAD DE LOS SOCIOS Y DE LOS ADMINISTRADORES}

El deber de lealtad consiste en la obligación de actuar en interés de la sociedad en caso de conflicto de intereses con ésta, subordinando los propios a favor de aquélla, salvo que ésta autorice tal actuación. Se trata de un deber que, junto al deber de cuidado del interés ajeno, deriva del deber de fidelidad, que al mismo tiempo ha de encuadrarse dentro del deber de diligencia y, en último término, en el deber genérico de buena fe. Por otra parte, se trata de un deber que afecta a las relaciones de gestión y de colaboración. Así, el deber de lealtad debe predicarse tanto respecto de los socios como de los administradores o gestores, imponiendo la obligación de orientar su actuación o gestión hacia la promoción del interés social, así como la de perseguir éste con preferencia a cualquier otro, o no actuar de forma incompatible con él. De este modo, el ámbito propio en el que opera el deber de lealtad será el de los conflictos 
de intereses, implicando normalmente la prohibición de realizar ciertas conductas cuando supongan subordinar el interés social al propio o, en su caso, al de terceros (Ribas, 2010; Ribas, 2012; Oriol, 2013; Fernández de la Gándara, 2010.I).

Por lo que respecta a los socios, se trata de un deber que aquéllos asumen como consecuencia del propio contrato de sociedad, del que, lejos de ser un contrato limitado a establecer unas relaciones sociales, nace una sociedad como organización y como instrumento para conseguir un determinado fin común (Coutinho, 2002). Esto es, con el nacimiento de la sociedad surge un interés social propio e independiente al que pueda corresponder a los socios individualmente considerados, o incluso al de la mayoría de los socios (ver Arroyo, 2002), siendo el fin común el elemento vertebrador del contrato de sociedad. El deber de fidelidad del socio encontraría su origen en este fin común, implicando el deber general de promover el fin social, y de ejercer sus derechos y actividades con respeto a tal fin, debiendo subordinar sus intereses propios a éste (Ribas, 2010; Irakulis, 2013; Fernández de la Gándara, 2010.II refiriéndose a las sociedades limitadas-). Ciertas posturas doctrinales consideran que el deber de lealtad no está vinculado a la condición de socio, sino a la de socio relevante (en especial, los socios de control), por lo que no afectaría a todos los socios ni a todas las sociedades. Rechazamos esta postura al entender el deber de lealtad como consustancial a la condición de socio, derivado de la buena fe y del deber de colaborar en la consecución del fin común. Cosa diferente es que la intensidad del deber de lealtad pueda variar atendiendo a la clase de sociedad de que se trate, en especial si se trata de una sociedad de rasgos personalistas o no ${ }^{3}$.

En cuanto a los administradores o gestores, debe partirse de que, por definición, éstos están al servicio de la consecución de los fines sociales, que es un interés ajeno al propio (Ribas, 2010). Desde una perspectiva histórica, la separación entre la propiedad del capital y el control efectivo y la gestión del empresario (la sociedad), han tenido como consecuencia la necesidad de establecer mecanismos de control de la actuación de los administradores o gestores, en especial para evitar que éstos supediten los intereses derivados de los fines sociales a los propios, esto es, para salvaguardar a la sociedad de una conducta desleal de aquéllos. Estos mecanismos son muy diversos: el sometimiento del órgano de administración a la junta o asamblea general (lo que en ciertos casos es más teórico que real), la delimitación legal y estatutaria de competencias de la administración, la posibilidad de impugnación de sus acuerdos, la regulación del funcionamiento del órgano de administración, el régimen de

\footnotetext{
${ }^{3}$ Sobre todo ello puede verse: Irakulis, (2013) y Alonso Espinosa, (1996).
} 
responsabilidad, las auditorías, la regulación de la capacidad para ser administrador, la extensión de la condición de administrador a personas al margen del órgano, etc. (Morillas, 2002).

Estas consideraciones son extensibles asimismo a las sociedades cooperativas, si bien deben tenerse en cuenta las particularidades propias de éstas, como el elemento mutual y la definición de la actividad cooperativizada (que forma parte de la causa del contrato de sociedad), o circunstancias como que al menos la mayoría de administradores deban ser socios de la cooperativa, estando éstos obligados a aceptar el cargo (en este sentido, en referencia a las normas sobre buen gobierno corporativo, Alfonso y Sánchez Ruiz, 2007). Como observamos en las siguientes páginas, sin embargo, el desarrollo de esta cuestión es distinta tanto entre las propias leyes de cooperativas como, notablemente, en comparación con la regulación de las sociedades de capital.

Este trabajo pretende ser un punto de partida para la reflexión y mejora de la legislación cooperativa, recogiendo de forma sistematizada y sucinta el estado de la regulación del deber de lealtad en la legislación relativa a esta clase de sociedades, y presentando una comparación genérica con la regulación de, en particular, las sociedades de capital. Se plantea, asimismo, una valoración preliminar sobre la cuestión. Para ello, se realiza en primer lugar un breve análisis de esta cuestión en la legislación societaria en general, y en la legislación sobre sociedades de capital en particular, presentando así la situación general y la relativa a las sociedades más comunes y referenciales desde el punto de vista jurídico en la práctica, para pasar, en segundo lugar, a mostrar la regulación concreta del deber de lealtad en las distintas leyes de cooperativas del Estado español y, finalmente, como se indicaba, presentar unas conclusiones y consideraciones preliminares.

\section{EL DEBER DE LEALTAD EN EL DERECHO DE SOCIEDADES. EN PARTICULAR, LA REGULACIÓN DE LAS SOCIEDADES DE CAPITAL}

Se recoge a continuación una breve descripción del estado de la cuestión en el Derecho de sociedades en general, y en la regulación de las sociedades de capital en particular, a los efectos de poder realizar una valoración preliminar de la legislación cooperativa a este respecto. 


\subsection{Las conductas desleales en la legislación societaria}

\subsubsection{Conductas desleales de los socios}

Las concreciones del deber de lealtad que se suelen señalar en relación a los socios son diversas $^{4}$, si bien las recogidas expresamente en el Real Decreto Legislativo 1/2010, de 2 de julio, por el que se aprueba el texto refundido de la Ley de Sociedades de Capital (LSC) son escasas:

a) Prohibición de alcanzar acuerdos que lesionen el interés social en beneficio de uno o varios socios o de terceros (art. 204): se trataría de acuerdos impugnables ${ }^{5}$. De este modo, queda patente que el interés de la sociedad sería un valor jurídico superior al de la mayoría (Arroyo, 2002).

b) Prohibición de voto en caso de conflicto de intereses: (art. 190 LSC) Cuando se trate de adoptar un acuerdo que autorice al socio a transmitir participaciones o acciones sujetas a una restricción legal o estatutaria, que le excluya de la sociedad, que le libere de una obligación o le conceda un derecho, o por el que se le facilite cualquier tipo de asistencia financiera, incluida la prestación de garantía, en su favor, así como cuando, siendo administrador, el acuerdo se refiera a la dispensa de las obligaciones derivadas del deber de lealtad. También se prevén otros supuestos en que en principio no se priva del derecho de voto al socio, aunque cabría la impugnación probándose el perjuicio.

Ha de indicarse que la doctrina también ha señalado en este punto las limitaciones de la mayoría en defensa de la minoría, y el deber de cooperar para alcanzar quórums reforzados (Fernández de la Gándara, 2010.II). El principal motivo que explicaría el escaso desarrollo del deber de lealtad de los socios en la LSC es que se trata de una regulación dirigida a las sociedades de capital, habiendo sido mayor el desarrollo del deber de lealtad en la regulación de las sociedades personalistas, dado que la colaboración e implicación del socio es más intensa en ellas (Coutinho, 2002; Ribas, 2010). Así, por lo general, en las sociedades de

\footnotetext{
${ }^{4}$ Así, por parte de la doctrina se han señalado algunas prohibiciones que se derivarían del deber de lealtad, que no están expresamente previstas por la legislación española, por ejemplo: usar informaciones societarias que perjudiquen a la sociedad; aprovechar en beneficio propio oportunidades de negocio de la sociedad, induciendo a la contraparte a negociar con él y no con la sociedad; difundir opiniones que desacrediten a la sociedad; impugnar acuerdos para presionar a la sociedad o a los socios dominantes; transmitir la participación social a un tercero "predador" (Coutinho, 2002; aunque hace referencia al Derecho portugués, son reflexiones válidas con carácter general).

${ }^{5}$ Sobre la configuración del derecho de voto del socio y las orientaciones al respecto, y sus limitaciones, puede verse: Fernández de la Gándara (2010).
} 
capital los derechos de los socios han tenido un mayor desarrollo normativo que sus obligaciones. Asimismo, debe hacerse notar que, a pesar de que esta diferencia se haya suavizado, el deber de lealtad de los socios es algo más severo en las sociedades de responsabilidad limitada, de mayor carácter personalista, que en las anónimas (Irakulis, 2013; Alonso Espinosa, 1996).

Si atendemos a la regulación de las sociedades colectivas y comanditarias, se pueden añadir al menos otras dos concreciones del deber de lealtad de los socios:

c) Prohibición de competencia: De acuerdo con los arts. 136 y 137 del Código de Comercio (CCo), en las sociedades colectivas que no tengan género de comercio determinado, sus socios no podrán hacer operaciones por cuenta propia sin previo consentimiento de la sociedad. Si el género de comercio estuviera determinado, los socios no podrían hacer negocios pertenecientes a tal especie, salvo pacto en contrario.

d) Prohibición de exigir la disolución de la sociedad cuando con motivo de ello se pretenda hacer un lucro particular que no hubiera obtenido subsistiendo la compañía: El resto de socios podría oponerse a la disolución de la sociedad constituida por tiempo indefinido por entender que el socio ha actuado con mala fe (art. 224 CCo).

\subsubsection{Conductas desleales de los administradores}

La doctrina y la legislación referentes al deber de lealtad de los administradores han tenido un desarrollo mucho mayor ${ }^{6}$. La LSC incluye diversas concreciones de este deber, que además han tenido un significativo desarrollo mediante la aprobación de la Ley 31/2014, de 3 de diciembre, que modifica la Ley de Sociedades de Capital para la mejora del gobierno corporativo:

\footnotetext{
${ }^{6}$ Debido a la finalidad y extensión de este trabajo, no desarrollamos completamente este punto, sino que enumeramos las concreciones del deber de lealtad en la LSC, incluyendo en algún caso un breve comentario. No obstante, téngase en cuenta que se trata una cuestión sobre la que existe una profusa literatura jurídica que nos puede ayudar a comprender mejor este tema y profundizar en él. Como muestra de ello, señalamos, entre otros, Oriol, 2013; Fernández de la Gándara, 2010.I; Ribas 2010; Ribas, 2012; etc.

En cuanto a los deberes que indica la doctrina comparada, son generalmente aceptados, por ejemplo, los deberes de: actuar en el campo o ámbito de sus poderes; realizar un juicio independiente; actuar de buena fe para promover el éxito de la sociedad; obtener la autorización de la sociedad para realizar transacciones con ésta; no explotación personal de la propiedad, información u oportunidades de la sociedad, u obtención de un tercero un beneficio por ejercer sus funciones de una forma determinada (Davies/Worthington, 2012; concreciones del deber de lealtad aplicables también en nuestro ordenamiento).

Por otro lado, aunque no se ahonda en ello, habría que tener en cuenta, en su caso, las limitaciones establecidas para las sociedades cotizadas por la Ley del Mercado de Valores.
}

REVESCO N 120 - Primer Cuatrimestre 2016 - ISSN: 1885-8031 - www.ucm.es/info/revesco 
a) Previsión general del deber de lealtad (art. 227): "Los administradores deberán desempeñar el cargo con la lealtad de un fiel representante, obrando de buena fe y en el mejor interés de la sociedad".

b) No ejercitar sus facultades con fines distintos de aquéllos para los que le han sido concedidas (art. 228.a): se configura como una de las obligaciones básicas derivadas del deber de lealtad.

c) Deber de actuar bajo el principio de responsabilidad personal, con libertad de criterio e independencia respecto de instrucciones y vinculaciones de terceros (art. 228.d).

d) Deber de información o transparencia (disclosure): (art. 229.3): comunicar toda situación de conflicto directa o indirecta con el interés social. Estas situaciones deben ser, además, objeto de información en la memoria.

e) Prohibición de voto en caso de conflicto de intereses (art. 228.c): se prohíbe participar en la toma de acuerdos en las que él o una persona vinculada tenga un conflicto de intereses directo o indirecto (salvo que le afecte como administrador). Ha de recordarse lo señalado en el art. 190.

f) Deber genérico de evitar situaciones de conflicto (art. 228.e): deber de adoptar las medidas necesarias para evitar incurrir en situaciones en las que sus intereses, por cuenta propia o ajena, puedan entrar en conflicto con el interés social y con sus deberes para con la sociedad.

g) Prohibición de utilizar el nombre de la sociedad y de invocar la condición de administrador (art. 229.1.b): "para influir indebidamente en la realización de operaciones privadas".

h) Prohibición de aprovechar oportunidades de negocio de la sociedad (art. 229.1.d).

i) Prohibición de tener un interés opuesto al de la sociedad (indirectamente, en el art. 224.2, cuando regula el cese de los administradores en las sociedades anónimas).

j) Prohibición de competencia (art. 229.1.f): actividades que entrañen una competencia efectiva, sea actual o potencial, o que, de cualquier otro modo, le sitúen en un conflicto permanente con los intereses de la sociedad. 
k) Prohibición de ser administrador de los funcionarios al servicio de la Administración pública con funciones a su cargo que se relacionen con las actividades propias de las sociedades de que se trate (art. 213.2).

1) Abstenerse de realizar transacciones con la sociedad (autocontratación) (art. 229.1.a): Se exceptuarían las operaciones ordinarias, hechas en condiciones estándar para los clientes y de escasa relevancia.

m) Prohibición de hacer uso de los activos sociales, incluida la información confidencial de la compañía, con fines privados (art. 229.1.c).

n) Deber de guardar secreto de la información confidencial (art. 228.b): sobre informaciones, datos, informes o antecedentes que conozcan por el ejercicio del cargo. Persiste tras el cese en el cargo. Se exceptúan los casos en que la ley lo permita o requiera.

o) La regulación de la retribución: Se prevén distintos sistemas de remuneración y en particular la remuneración mediante participación en beneficios y mediante entrega de acciones. Se recogen ciertas reglas para su fijación, debiendo la junta general aprobar el importe máximo de la retribución del conjunto. Deberá guardar una proporción razonable con la importancia de la sociedad, su situación económica de cada momento y los estándares de mercado de empresas comparables, debiendo estar el sistema de remuneración orientado a promover la rentabilidad y sostenibilidad a largo plazo de la sociedad e incorporar las cautelas necesarias para evitar la asunción excesiva de riesgos y la recompensa de resultados desfavorables. (arts. 217-219).

p) Prohibición de obtener ventajas o remuneraciones de terceros distintos de la sociedad y su grupo asociadas al desempeño de su cargo, salvo que se trate de atenciones de mera cortesía (art. 229.1.e). El administrador no puede obtener de su gestión ventajas derivadas de conductas oportunistas que no sean las pactadas con la sociedad (Ribas, 2010; Paz-Ares, 2013).

\subsection{Sujetos afectados por el deber de lealtad en la LSC}

En principio estos deberes corresponden a los socios y/o miembros del órgano de administración de la sociedad, pero en ocasiones se extienden también a las personas vinculadas a ellos, fundamentalmente al administrador (ver art. 229.2). El art. 231 delimita el 
concepto de persona vinculada, tomando en consideración si el administrador es persona física ${ }^{7}$ o jurídica ${ }^{8}$.

\subsection{Régimen de imperatividad y dispensa en la LSC}

El art. 230 establece que el régimen relativo al deber de lealtad es imperativo. No obstante, permite en ciertos casos la dispensa de las prohibiciones del proyectado art. 229. Atendiendo a la actuación concreta de que se trate, el acuerdo sobre la dispensa correspondería a la junta general o al órgano de administración, siendo el régimen más estricto el relativo a la dispensa de la prohibición de competencia. Han de tenerse en cuenta las mayorías reforzadas en la junta en el caso de la sociedad limitada (art. 199.b).

\subsection{Consecuencias del incumplimiento en la LSC}

- Impugnación de los acuerdos sociales: son anulables cuando lesionen el interés social en beneficio de uno o varios socios o de terceros (ver art. 190 en cuanto a la carga de la prueba). Del art. 251 ha de deducirse que los acuerdos del consejo de administración son también impugnables en este caso.

- Cese: En cuanto a los socios, habrá de estarse a las causas de exclusión previstas en los estatutos (art. 351). Por su parte, el cese de los administradores es posible en cualquier momento, aunque no conste en el orden del día: es posible exigir mayorías reforzadas en las sociedades limitadas (art. 223); en las sociedades anónimas, existe la obligación de cese, a solicitud de cualquier socio, cuando incurran en cualquier prohibición legal o tengan intereses opuestos a los de la sociedad (art. 224). La realización de actividades competitivas con la sociedad conllevará el cese a petición de cualquier socio, cuando el riesgo haya devenido relevante (art. 230.3).

- Responsabilidad: Los administradores de derecho o de hecho responderán frente a la sociedad, los socios y los acreedores sociales del daño que causen por actos u omisiones

\footnotetext{
${ }^{7}$ a) El cónyuge o personas con análoga relación de afectividad; b) Los ascendientes, descendientes y hermanos (así como los de su cónyuge); c) Los cónyuges de los ascendientes, de los descendientes y de los hermanos del administrador; d) Las sociedades en las que, por sí o por persona interpuesta, tenga una posición de control.

8 a) Los socios que tengan, respecto del administrador persona jurídica, una posición de control de; b) Sus administradores, de derecho o de hecho, liquidadores y apoderados con poderes generales; c) Las sociedades que formen parte del mismo grupo y sus socios; c) Las personas que respecto de su representante tengan la consideración de personas vinculadas al administrador persona física.

Subraya las carencias a este respecto: Ribas, 2012.
}

REVESCO No 120 - Primer Cuatrimestre 2016 - ISSN: 1885-8031 - www.ucm.es/info/revesco 
contrarios a la ley o a los estatutos o por los realizados incumpliendo los deberes inherentes al desempeño del cargo (arts. 236-241bis). Asimismo, la infracción del deber de lealtad determinará también el deber de devolver a la sociedad el enriquecimiento injusto obtenido (art. 227.2). Además, el ejercicio de acciones de responsabilidad no obstaría al ejercicio de las acciones de impugnación, cesación, remoción de efectos y, en su caso, anulación de los actos y contratos celebrados por los administradores con violación de su deber de lealtad (art. 232).

\section{EL DEBER DE LEALTAD EN LA LEGISLACIÓN COOPERATIVA}

En las siguientes páginas se recogen mediante diferentes tablas las distintas concreciones del deber de lealtad de los socios y de los administradores de las cooperativas previstas en las leyes de cooperativas del Estado español.

Ha de advertirse que este estudio no abarca la totalidad de las previsiones legales al respecto, dado que, con el objetivo de mantener cierta uniformidad y generalidad, se ha optado por no incluir especialidades de clases particulares de socios (que no sean socios cooperadores), órganos sociales diferentes de la asamblea general o el órgano de administración (comité de recursos, consejo social, intervención -aunque en este caso se compartan muchas de las previsiones establecidas para la administración-, etc.; al mismo tiempo se han excluido las referencias a los directores o gerentes) o tipos especiales de cooperativas (p. ej. cooperativas de crédito) .

Al mismo tiempo, se ha tratado de agrupar los diferentes preceptos en los casos en que su redacción es igual o muy similar, lo que no siempre ha resultado fácil, dado que los legisladores cooperativos han optado en ocasiones por introducir matices de mayor o menor importancia en las correspondientes leyes de cooperativas, lo que también se ha intentado reflejar en este trabajo (es notorio, por ejemplo, el caso de la prohibición de competencia). En este sentido han de entenderse también las referencias al órgano de administración, que engloba en general al consejo rector u otros tipos de organización de la administración. 


\subsection{Deber de lealtad de los socios}

a) Declaración general del deber lealtad

\begin{tabular}{|l|l|}
\hline CONTENIDO & CONSECUENCIAS DEL INCUMPLIMIENTO \\
\hline $\begin{array}{l}\bullet \text { Obligación de guardar lealtad a la } \\
\text { cooperativa }\left(27 . c L F C N^{9}\right)\end{array}$ & $\begin{array}{l}\bullet \text { Normas de disciplina social, autorregulación (28 } \\
L F C N)\end{array}$ \\
\hline
\end{tabular}

b) Prohibición de alcanzar acuerdos que lesionen, en beneficio de uno o varios socios, o de terceros, los intereses de la sociedad cooperativa

\begin{tabular}{|l|l|}
\hline CONTENIDO & CONSECUENCIAS INCUMPLIMIENTO \\
\hline Prohibición de alcanzar acuerdos que & - Acuerdos anulables (31.1 LCoop, 35.1 LCAnd, \\
lesionen, en beneficio de uno o varios & 36.1 LCAr, 57.1 LCAs, 42.1 LCCan, 38.1 LCCat, \\
socios, o de terceros, los intereses de la &, 54.1 LCCLM, 40.1 LCCV, 39.1 LCCYL, 39.1 \\
sociedad cooperativa (regulación & LCE, 35.1 LCEX, 40.1 LCG, 46.1 LCIB, 38.1 \\
$\begin{array}{l}\text { indirecta, al regular los acuerdos } \\
\text { anulables) }\end{array}$ & LCMa, 47.1 LCMu, 44.1 LCR, 36.2 LFCN) \\
\hline
\end{tabular}

c) Prohibición de voto en caso de conflicto de intereses y otras medidas relativas a la toma de decisiones

\begin{tabular}{|c|c|}
\hline CONTENIDO & $\begin{array}{l}\text { CONSEC. } \\
\text { INCUMPL. }\end{array}$ \\
\hline $\begin{array}{l}\text { - La persona socia que se vea implicada en un eventual conflicto de intereses } \\
\text { no podrá tomar parte en la votación del correspondiente órgano }(52.2 \\
L C A n d) \\
\text { - Los estatutos podrán establecer los supuestos en los que el socio deba } \\
\text { abstenerse }(37.7 L C C a n, 37.6 L C C V, 35.5 L C C Y L) \\
\text { - Los estatutos establecerán/deberán establecer los supuestos en que el socio } \\
\text { deba abstenerse de votar }(26.8 L C o o p, 52.1 L C A s, 49.7 L C C L M, 35.5 L C E \text {, } \\
\text { 33.4 LCEx, } 36.7 L C G, 25.6 L C M a, 44.8 L C M u, 41.6 L C R) \\
\text { - En todo caso: } \\
\text { - Para la adopción de un acuerdo que le excluya de la sociedad, le libere }\end{array}$ & $\begin{array}{l}\text { - No } \\
\text { expresamente } \\
\text { previsto } \\
\text { (acuerdo } \\
\text { anulable) }\end{array}$ \\
\hline
\end{tabular}

\footnotetext{
9 Abreviaturas empleadas: Ley 27/1999, de 16 de julio, de cooperativas (LCoop), Ley 14/2011, de 23 de diciembre, de cooperativas andaluzas (LCAnd), Decreto Legislativo 2/2014, de 29 de agosto, del Gobierno de Aragón, por el que se aprueba el texto refundido de la Ley de Cooperativas de Aragón (LCAr), Ley 4/2010, de 29 de junio, de cooperativas de Asturias (LCAs), Ley 6/2013, de 6 de noviembre, de cooperativas de Cantabria (LCCan), Ley 18/2002, de 5 de julio, de cooperativas de Cataluña (LCCat), Ley 11/2010, de 4 de noviembre, de cooperativas de Castilla la Mancha (LCCLM), Ley 8/2003, de 24 de marzo, de cooperativas de la Comunidad Valenciana (LCCV), Ley 4/2002, de 11 de abril, de cooperativas de Castilla y León (LCCYL), Ley 4/1993, de 24 de junio, de cooperativas de Euskadi (LCE), Ley 2/1998, de 26 de marzo, de sociedades cooperativas de Extremadura (LCEx), Ley 5/1998, de 18 de diciembre, de cooperativas de Galicia (LCG), Ley 1/2003, de 20 de marzo, de cooperativas de las Illes Balears (LCIB), Ley 4/1999, de 30 de marzo, de cooperativas de Madrid (LCMa), Ley 8/2006, de 16 de noviembre, de sociedades cooperativas de Murcia (LCMu), Ley 4/2001, de 2 de julio, de cooperativas de La Rioja (LCR), Ley Foral 14/2006, de 11 de diciembre, de cooperativas de Navarra (LFCN).
}

REVESCO N 120 - Primer Cuatrimestre 2016 - ISSN: 1885-8031 - www.ucm.es/info/revesco 
de una obligación o le conceda un derecho, o por el que la sociedad decida anticiparle fondos, concederle crédito o préstamos, prestar garantías a su favor o facilitarle cualquier asistencia financiera, y cuando, siendo administrador, el acuerdo se refiera a la dispensa de la prohibición de competencia (51.1 LCAs, 49.7 LCCLM)

- En los supuestos previstos para las sociedades de responsabilidad limitada (26.8 LCoop, 44.8 LCMu)

- Deber de abstención de las personas afectadas en los supuestos de acuerdos sobre expedientes sancionadores, de ratificación de las sanciones objeto de recurso, y del ejercicio de acción de responsabilidad o de cese de los miembros de órganos sociales $(33.3$ LCCat)

- Cuando en el orden del día figuren asuntos que afecten directamente a quien haya de ejercer las funciones de presidente y/o secretario de la asamblea general / cuando exista un conflicto de intereses:

- Deber de elegir entre los socios presentes a quien los sustituya en dicha función (34.2.II LCCYL, 35.4.IV LCG, 41.4 LCIB)

- Se estará a lo que reglamentariamente se establezca, sin perjuicio de los estatutos (60.5 LCAnd)

- Sustitución del presidente y secretario, en principio miembros del consejo rector (33.3 LCMa, 39.2 LCR)

d) Prohibición de competencia

\begin{tabular}{|c|c|c|}
\hline CONT & & INCUMPLIM. \\
\hline $\begin{array}{l}\text { - No realizar actividades competitivas con la } \\
\text { actividad empresarial de la cooperativa (15.2.f } \\
\text { LCoop, 28.e LCAs, 20.2.f LCCAn, 33.e LCCLM, } \\
\text { 22.2.e LCEx, 21.2.g LCIB, 28.2.f LCMu) } \\
\text { - ni colaborar con quien las realice (28.e LCAs, } \\
\text { 33.e LCCLM, 22.2.e LCEx) } \\
\text { - No dedicarse a actividades que puedan competir } \\
\text { con las finalidades/los fines sociales de la } \\
\text { cooperativa ni colaborar con quien las realice } \\
\text { (26.1.f LCCat, 20.e LCAr) } \\
\text { - No realizar actividades en competencia con las } \\
\text { que sean objeto de la cooperativa (23.2.f LCCYL) } \\
\text { - No realizar actividades competitivas con el } \\
\text { objeto social, ni colaborar con quien las realice } \\
\text { (22.d LCE, 23.1.c } L C M a, 26 . d L C R)\end{array}$ & $\begin{array}{l}\text { administración } \\
\text { 15.2.f LCoop, } \\
\text { 20.d LCAn, } \\
\text { 20.e LCAr, } \\
\text { 28.e LCAs, } \\
\text { 20.2.f LCCan, } \\
\text { 26.1.f LCCat, } \\
\text { 33.e LCCLM, } \\
\text { 23.2.f LCCYL, } \\
\text { 21.2.f LCIB, } \\
\text { 22.d LCE, } \\
\text { 22.2.e LCEx, } \\
\text { 24.d LCG, } \\
\text { 23.1.c LCMa, } \\
\text { 28.2.f LCMu, } \\
\text { 26.d LCR) } \\
\text { - Asamblea } \\
\text { General } \\
\text { (32.2.d } \\
\text { LCCan, pero } \\
\text { contradicción }\end{array}$ & $\begin{array}{l}\text { - Normas de } \\
\text { disciplina social, } \\
\text { autorregulación } \\
\text { (18 LCoop, } 21 \\
\text { LCAnd, } 24 \text { LCAr, } \\
21 \text { LCCat, } 24 \\
\text { LCCYL, } 29 L C E \text {, } \\
28 L C E x, 25 \\
\text { LCG, } 28 L C I B, \\
25 L C M a, 32 \\
L C M u, 28 L C R \text {, } \\
28 L F C N \text { ) } \\
\text { - Falta muy grave } \\
\text { (expulsión) } \\
\text { (29.2.a LCCan) } \\
\text { - Posibilidad de } \\
\text { ser considerada } \\
\text { falta muy grave, } \\
\text { pudiendo ser } \\
\text { motivo de } \\
\text { expulsión (40 } \\
\text { LCAs, } 32.2 . a\end{array}$ \\
\hline
\end{tabular}

REVESCO No 120 - Primer Cuatrimestre 2016 - ISSN: 1885-8031 - www.ucm.es/info/revesco 


\begin{tabular}{|l|l|l|}
\hline$L C R)$ & $\begin{array}{l}\text { LCCan; 37.2.d } \\
\text { LCMu, pero } \\
\text { contradicción } \\
\text { con 28.2.f } \\
\text { - NCMu) }\end{array}$ & $\begin{array}{l}\text { LCCLM, 23.2.a } \\
\text { LCCV) }\end{array}$ \\
$\begin{array}{l}\text { las propias de la cooperativa ni colaborar con } \\
\text { quien las realice (20.d LCAnd) }\end{array}$ & $\begin{array}{l}\text { - Asamblea } \\
\text { general o } \\
\text { consejo rector } \\
\text { - Evitar todo tipo de competencia (27.c LFCN) }\end{array}$ & \\
- Posibilidad de recoger el principio de & \\
exclusividad en los estatutos $(14.1 . h L C C L M)$ &
\end{tabular}

e) Prohibición de tener un fin y objeto social contrarios a los principios cooperativos y/o objeto social de la cooperativa

\begin{tabular}{|l|l|}
\hline CONTENIDO & $\begin{array}{l}\text { CONSECUENCIAS } \\
\text { INCUMPLIMIENTO }\end{array}$ \\
\hline $\begin{array}{l}\text { - Prohibición de ser socio de personas cuyo fin y objeto social } \\
\text { contrarios a los principios cooperativos y/o objeto social de la } \\
\text { cooperativa }(16.1 L C A r, 19.1 L C C V, 19.1 \mathrm{LCEx})\end{array}$ & \\
\hline
\end{tabular}

f) Prohibición de pertenecer a una cooperativa a título de empresario, contratista, capitalista u otro análogo, respecto de aquélla o de los socios como a tales

\begin{tabular}{|l|l|}
\hline CONTENIDO & $\begin{array}{l}\text { CONSECUENCIAS } \\
\text { INCUMPLIMIENTO }\end{array}$ \\
\hline
\end{tabular}

- Prohibición de ser socio a título de empresario, contratista, capitalista u otro análogo, respecto de aquella o de los socios como a tales (16.2 LCAr, 21.3 LCAs, 19.2 LCEx, 18.3 LCG, 19.2 $L C I B, 20.3$ LCR $)$

g) Deber de secreto

\begin{tabular}{|c|c|}
\hline CONTENIDO & $\begin{array}{l}\text { CONSECUENCIAS } \\
\text { INCUMPLIMIENTO }\end{array}$ \\
\hline $\begin{array}{l}\text { - Deber de guardar secreto sobre asuntos/actividades y } \\
\text { datos de la cooperativa cuya divulgación pueda } \\
\text { perjudicar a los intereses sociales (lícitos) de la misma } \\
\text { (15.2.c LCoop, 20.e LCAnd, 20.f LCAr, 28.d LCAs, } \\
\text { 20.2.c LCCan, 26.1.h LCCat, 33.d LCCLM, 27.g } \\
L C C V, 23.2 . c L C C Y L, 22 . e \text { LCE, 22.2.d LCEx, 24.e } \\
L C G, 21.2 . d L C I B, 23.1 . c L C M a, 28.2 . c L C M u, 26 . e \\
L C R) \\
\text { - Obligación de guardar secreto profesional de las } \\
\text { actividades, proyectos y planes en relación con terceros } \\
(27 . c L F C N)\end{array}$ & $\begin{array}{l}\text { - Normas de disciplina social, } \\
\text { autorregulación (18 LCOop, } 21 \\
L C A n d, 24 L C A r, 37 L C A s, 28 \\
L C C a n, 21 L C C a t, 38 L C C L M, 23.1 \\
L C C V, 24 L C C Y L, 29 L C E, 28 \\
L C E x, 25 L C G, 28 L C I B, 25 L C M a \text {, } \\
32 L C M u, 28 L C R, 28 L F C N) \text {. } \\
\text { - (posibilidad de ser considerada } \\
\text { falta muy grave por ser una } \\
\text { actuación que perjudica los intereses } \\
\text { de la cooperativa, ver } i \text { ) }\end{array}$ \\
\hline $\begin{array}{l}\text { - Prohibición de utilización de la información } \\
\text { conseguida en virtud del derecho de información para }\end{array}$ & \\
\hline
\end{tabular}


una finalidad diferente de la amparada por el mismo, o incompatibles con aquellas para los que los datos

hubieran sido recogidos (36.4 LCCLM)

h)_Prohibición de prevalerse de la condición de socio para realizar actividades especulativas o ilícitas

\begin{tabular}{|c|c|}
\hline CONTENIDO & $\begin{array}{l}\text { CONSECUENCIAS } \\
\text { INCUMPLIMIENTO }\end{array}$ \\
\hline $\begin{array}{l}\text { - Prohibición de prevalerse de la condición de socio } \\
\text { de la cooperativa para realizar actividades } \\
\text { especulativas o ilícitas (40.2 LCAs, 29.2.e LCCan, } \\
\text { 32.2.e LCCLM, 23.2.e LCCV) } \\
\text { - Deber de evitar cualquier posibilidad de prevalerse } \\
\text { de la condición de socio para desarrollar actividades } \\
\text { especulativas, fraudulentas o contrarias a las leyes } \\
\text { (27.c } L F C N)\end{array}$ & $\begin{array}{l}\text { - Falta muy grave (expulsión) (29.2.e } \\
\text { LCCan) } \\
\text { - Posibilidad de ser considerada falta } \\
\text { muy grave, y motivo de expulsión } \\
(40.2 \text { LCAs, 32.2.e LCCLM, 23.2.a } \\
\text { LCCV) } \\
\text { - Normas de disciplina social, } \\
\text { autorregulación }(28 L F C N)\end{array}$ \\
\hline
\end{tabular}

i) Prohibición de realización de actividades que puedan perjudicar los intereses de la cooperativa

\begin{tabular}{|l|l|}
\hline CONTENIDO & CONSECUENCIAS \\
& INCUMPLIMIENTO \\
\hline - Prohibición de realización de actividades que & $\bullet$ Posibilidad de ser considerada falta \\
puedan perjudicar los intereses de la cooperativa & muy grave, pudiendo ser motivo de \\
$(40.2$ LCAs, 29.2.a LCCan, 32.2.a LCCLM, 23.2.a & expulsión (40.2 LCAs, 29.2.a LCCan, \\
LCCV $)$ & 32.2.a LCCLM, 23.2.a LCCV) \\
\hline
\end{tabular}

j) Prohibición de descredito o de manifestaciones que puedan perjudicar a la cooperativa

\begin{tabular}{|l|l|}
\hline CONTENIDO & $\begin{array}{l}\text { CONSECUENCIAS } \\
\text { INCUMPLIMIENTO }\end{array}$ \\
\hline $\begin{array}{l}\text { • Prohibición de manifestaciones que puedan perjudicar los } \\
\text { intereses de la cooperativa (23.2.a LCCV) }\end{array}$ & $\begin{array}{l}\bullet \text { Posibilidad de ser considerada } \\
\text { falta muy grave, pudiendo ser } \\
\text { motivo de expulsión }(40.2\end{array}$ \\
$\begin{array}{l}\text { - Prohibición de actuaciones dirigidas al descrédito de la } \\
\text { cooperativa (40.2 LCAs, 29.2.a LCCan, 32.2.a LCCLM) }\end{array}$ & $\begin{array}{l}\text { LCAs, 29.2.a LCCan, 32.2.a } \\
\text { LCCLM, 23.2.a LCCV) }\end{array}$ \\
\hline
\end{tabular}

k) Respeto a los órganos de gobierno

\begin{tabular}{|l|l|}
\hline CONTENIDO & $\begin{array}{l}\text { CONSECUENCIAS } \\
\text { INCUMPLIMIENTO }\end{array}$ \\
\hline $\begin{array}{l}\text { Obligación de guardar respeto a los órganos de } \\
\text { gobierno (27.c } L F C N)\end{array}$ & $\begin{array}{l}\text { Normas de disciplina social, } \\
\text { autorregulación }(28 L F C N)\end{array}$ \\
\hline
\end{tabular}

1) Prohibición de la voluntad de beneficiarse indebidamente con la baja obligatoria

REVESCO No 120 - Primer Cuatrimestre 2016 - ISSN: 1885-8031 - www.ucm.es/info/revesco 


\begin{tabular}{|c|c|}
\hline CONTENIDO & $\begin{array}{l}\text { CONSECUENCIAS } \\
\text { INCUMPLIMIENTO }\end{array}$ \\
\hline $\begin{array}{l}\text { - Prohibición de tener una voluntad/un deliberado } \\
\text { propósito de beneficiarse indebidamente con la } \\
\text { baja obligatoria (24.1 LCAnd,35.1 LCAs, } 27.1 \\
L C C L M, 26.3 L C E x, 20.4 L C G, 21.4 L C M a, 31.1 \\
L C M u, 23.3 L C R) \\
\text { - O un propósito de eludir obligaciones ante la } \\
\text { sociedad }(24.1 L C A n d, 26.3 L C E x, 20.4 L C G \text {, } \\
\text { 21.4 LCMa, 31.1 LCMu, 23.3 LCR) } \\
\text { - Prohibición de causar baja para realizar } \\
\text { actividades competitivas con la cooperativa } \\
(26.5 . a L C E)\end{array}$ & $\begin{array}{l}\text { - Consideración de la baja como no } \\
\text { justificada (24.1 LCAnd, 35.1 LCAs, 27.1 } \\
L C C L M, 26.5 . a L C E, 26.3 L C E x, 20.4 \\
L C G, 21.4 L C M a, 31.1 L C M u, 23.3 \\
L C R \text { ) } \\
\text { - O expulsión (35.1 LCAs, } 27.1 \\
\quad L C C L M) \\
\text { - Indemnización de los daños y } \\
\text { perjuicios derivados de su actuación } \\
\text { antijurídica y fraudulenta (35.1 LCAs, } \\
\text { 27.1 LCCLM) }\end{array}$ \\
\hline
\end{tabular}

\subsection{Deber de lealtad de los administradores}

a) Previsión general (específica) del deber de lealtad

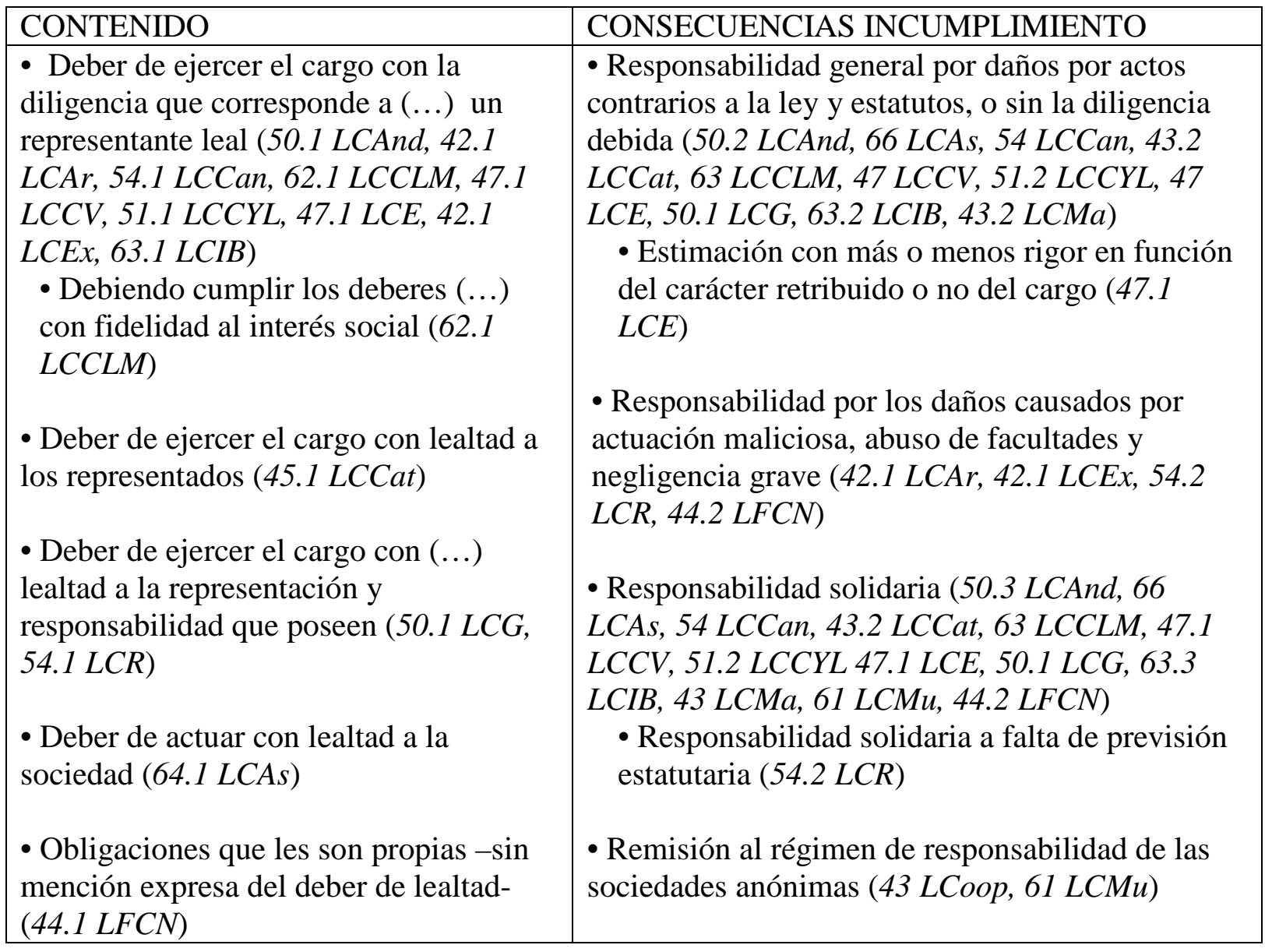

b) Prohibición de extralimitación en sus facultades

\begin{tabular}{|l|l|}
\hline CONTENIDO & CONSECUENCIAS INCUMPLIMIENTO \\
\hline$\bullet$ Prohibición de extralimitarse en sus & $\bullet$ Responsabilidad por daños - ver $a)-(47$ \\
\hline
\end{tabular}

REVESCO Nº 120 - Primer Cuatrimestre 2016 - ISSN: 1885-8031 - www.ucm.es/info/revesco 
facultades (47.1 LCCV, 43.2 LCMa) LCCV, 43.2 LCMa)

c) Prohibición de adoptar acuerdos que lesionen, en beneficio de uno o varios socios o terceros, los intereses de la sociedad

\begin{tabular}{|c|c|}
\hline CONTENIDO & CONSECUENCIAS INCUMPLIMIENTO \\
\hline $\begin{array}{l}\text { - Prohibición de alcanzar acuerdos que } \\
\text { lesionen, en beneficio de uno o varios } \\
\text { socios, o de terceros, los intereses de la } \\
\text { sociedad cooperativa (regulación } \\
\text { indirecta, al regular los acuerdos } \\
\text { anulables) }\end{array}$ & $\begin{array}{l}\text { - Acuerdo impugnable (41 LCAnd, 47.1 LCCat, } \\
\text { 46.6 LCCV, 49.1 LCE, 43.1 LCEx, 52.1 LCG, } \\
\text { 44.1 LCMa, 55.1 LCR) } \\
\text { (aunque en otros casos no se mencione } \\
\text { expresamente como motivo de impugnación, } \\
\text { posibilidad) }\end{array}$ \\
\hline
\end{tabular}

d) Prohibición de tener un interés opuesto al de la sociedad

\begin{tabular}{|c|c|c|}
\hline CONTENIDO & DISPENSA & $\begin{array}{l}\text { CONSECUENCIAS } \\
\text { INCUMPLIMIENTO }\end{array}$ \\
\hline $\begin{array}{l}\text { - Tener, (o pasar a } \\
\text { tener) bajo cualquier } \\
\text { forma intereses } \\
\text { opuestos a los de la } \\
\text { cooperativa (51.1.c } \\
\text { LCCan, 57.5.d } \\
\text { LCCLM, 42.1.C LCE, } \\
\text { 48.1.c LCG, 43.6.II } \\
\text { LCMa, 52.1.d LCR) }\end{array}$ & $\begin{array}{l}\text { - Asamblea general (32.2.d } \\
\text { y 51.1.c LCCan, 57.5.d } \\
\text { LCCLM, 52.2 LCE, 48.1.c } \\
\text { LCG, 52.1.d LCR) } \\
\text { - Exigencia de } \\
\text { autorización expresa } \\
\text { (57.5.d LCCLM, 48.1.c } \\
\text { LCG, 52.1.d LCR) } \\
\text { - Exigencia de } \\
\text { autorización expresa en } \\
\text { cada caso (51.1.c LCCan) }\end{array}$ & $\begin{array}{l}\text { - Destitución a petición de } \\
\text { cualquier socio, sin perjuicio de } \\
\text { la posible responsabilidad por } \\
\text { conducta desleal (51.4 LCCan, } \\
48.3 \text { LCG, 52.1.d LCR) } \\
\text { - Destitución a petición de } \\
\text { cualquier socio (42.2 LCE, art. } \\
\text { 43.6.II LCMa) } \\
\text { - Deber de dimitir }(42.2 L C E)\end{array}$ \\
\hline
\end{tabular}

e) Prohibición de competencia

\begin{tabular}{|c|c|c|}
\hline CONTENIDO & DISPENSA & $\begin{array}{l}\text { CONSECUENCIAS } \\
\text { INCUMPLIMIENTO }\end{array}$ \\
\hline 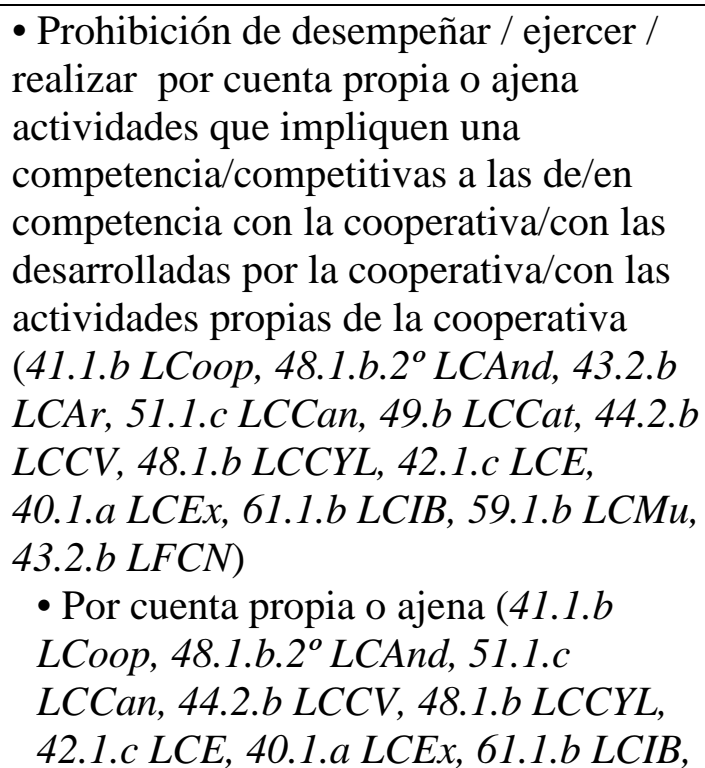 & $\begin{array}{l}\text { - Asamblea general } \\
\text { (41.1.b LCoop, 28.d y } \\
\text { 48.1.b. } 2^{\circ} \text { LCAnd, } 77.3 \\
\text { LCAs, 43.2.b LCAr, } \\
\text { 50.2 LCCat, 32.2.d y } \\
\text { 51.1.c LCCan, 57.5.d } \\
\text { y 62.2 LCCLM, 44.2.b } \\
\text { LCCV, 48.1.b LCCYL, } \\
\text { 42.2 LCE, 48.1.c } \\
\text { LCG, 37.2.d y 59.1.b } \\
\text { LCMu, 52.1.d LCR } \\
\text { 43.2.b LFCN) } \\
\text { • Mayoría reforzada } \\
\text { (77.3 LCAs, 43.2.b } \\
\text { LFCN) } \\
\text { • Exigencia de }\end{array}$ & $\begin{array}{l}\text { - Destitución / cese } \\
\text { (41.4 LCoop, } 48.2 \\
\text { LCAnd, 51.4 LCCan, } \\
57.7 \text { LCCLM, 45 LCCV, } \\
\text { 48.4 LCCYL, 42.2 LCE, } \\
\text { 48.3 LCG, 61.4 LCIB, } \\
\text { 59.4 LCMu, 52.3 LCR) } \\
\text { - A petición de } \\
\text { cualquier socio (41.4 } \\
\text { LCoop, 51.4 LCCan, } \\
\text { 48.4 LCCYL, 42.2 } \\
\text { LCE, 48.3 LCG, } 61.4 \\
\text { LCIB, 59.4 LCMu, } \\
\text { 52.3 LCR) } \\
\text { - Sin perjuicio de la } \\
\text { posible }\end{array}$ \\
\hline
\end{tabular}

REVESCO No 120 - Primer Cuatrimestre 2016 - ISSN: 1885-8031 - www.ucm.es/info/revesco 
59.1.b LCMu, 43.2.b LFCN)

- Actividades competitivas o complementarias (41.1.b LCoop, 48.1.b. $2^{\circ}$ LCAnd, 44.2.b LCCV, 48.1.b LCCYL, 40.1.a LCEX, 61.1.b LCIB, 59.1.b LCMu)

- Actividades competitivas o coincidentes (43.2.b LFCN)

- Prohibición de desarrollar o ejercer por cuenta propia o ajena actividades que puedan resultar competitivas con las de la propia cooperativa (57.5.d LCCLM, 48.1.c LCG, 52.1.d LCR)

- Actividades que puedan resultar competitivas o complementarias (57.5.d LCCLM)

- Prohibición de dedicarse por cuenta propia ni ajena al mismo género de comercio que constituye el objeto de la sociedad (77.1 LCAs)

- Prohibición de dedicarse, por cuenta propia o ajena, a actividades iguales, análogas o complementarias a las que constituyan el objeto social de la cooperativa (28.d LCAnd, 62.2 LCCLM)

- Prohibición de realización, por parte de los miembros de los órganos de administración, en su propio nombre o interés o en el de sus familiares hasta el segundo grado, de operaciones que puedan entrar en colisión con los intereses de la cooperativa (114.4.k $L C C V$ )

- Prohibición de desempeñar cargos en sociedades no filiales, cuando existan coincidencias o identidades por el objeto social (43.2.s LFCN)

- Prohibición de dedicarse por cuenta propia a administrar otra sociedad que se dedique al mismo o análogo género de actividad (64.3 LCAs) autorización expresa

(48.1.b. $2^{\circ}$ LCAnd,

43.2.b LCAr, 50.2

LCCat, 57.5.dy

62.2 LCCLM, 44.2.b

$L C C V$, 48.1.c LCG,

59.1.b LCMu, 52.1.d

$L C R)$

- Exigencia de autorización expresa en cada caso (41.1.b LCoop, 51.1.c

LCCan, 48.1.b $L C C Y L)$

- Consejo Rector (61.1.b LCIB) responsabilidad por conducta desleal (41.4 LCoop, 51.4 LCCan, 57.7

LCCLM, 48.4 LCCYL, 48.3 LCG, $59.4 \mathrm{LCMu}, 52.3$

$L C R)$

- Sin perjuicio de la posible responsabilidad en que pueda haber incurrido (61.4 $L C I B$ )

- Destitución a petición de cualquier socio cuando se esté incurso en causa de incompatibilidad legal o estatutaria -sin determinarlas- (art. 43.6.II LCMa)

- Deber de dimitir (42.2 $L C E$ )

- Asamblea General, autorización expresa (114.4.k LCCV)

- Consideración de infracción administrativa muy grave (114.4.k LCCV): sanción económica e inhabilitación (118.1 $L C C V$ )

- Asamblea general, mediante autorización expresa (64.3 LCAs)
- Petición de cese por cualquier socio (65.2 LCAs) 
f) Prohibición de ocupar altos cargos o ser personal al servicio de la Administración con funciones relacionadas con las actividades de las cooperativas

\begin{tabular}{|c|c|c|}
\hline CONTENIDO & DISPENSA & $\begin{array}{l}\text { CONSECUENCIAS } \\
\text { INCUMPLIMIENTO }\end{array}$ \\
\hline 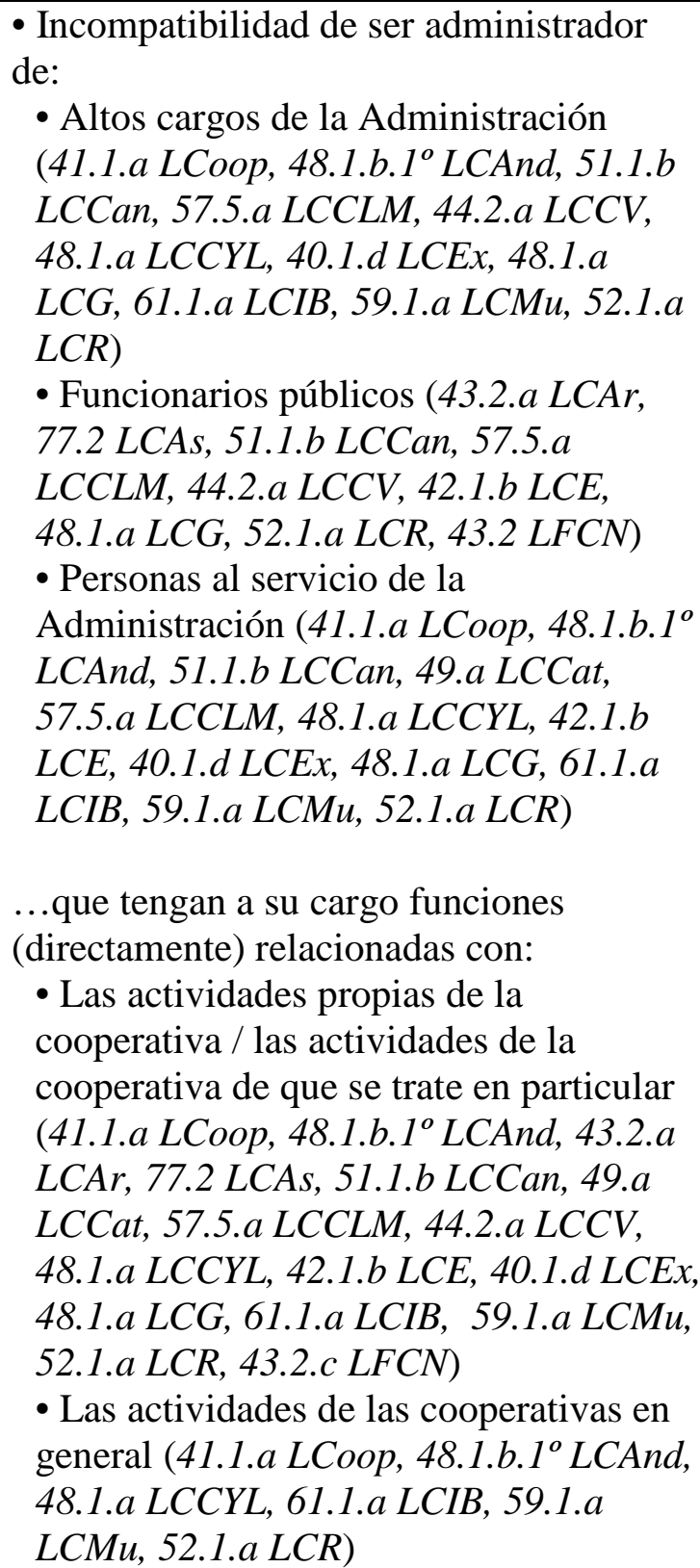 & $\begin{array}{l}\text { - Salvo que lo } \\
\text { sean en } \\
\text { representación } \\
\text { del ente } \\
\text { público en el } \\
\text { que presten sus } \\
\text { servicios } \\
\text { (41.1.a LCoop, } \\
\text { 48.1.b.1 } \\
\text { LCAnd, 43.2.a } \\
\text { LCAr, 51.1.b } \\
\text { LCCan, 57.5.a } \\
\text { LCCLM, } \\
\text { 48.1.a } L C C Y L \text {, } \\
\text { 40.1.d } L C E x \text {, } \\
\text { 48.1.a } L C G \text {, } \\
\text { 61.1.a } L C I B, \\
\text { 59.1.a } L C M u, \\
\text { 52.1.a } L C R)\end{array}$ & 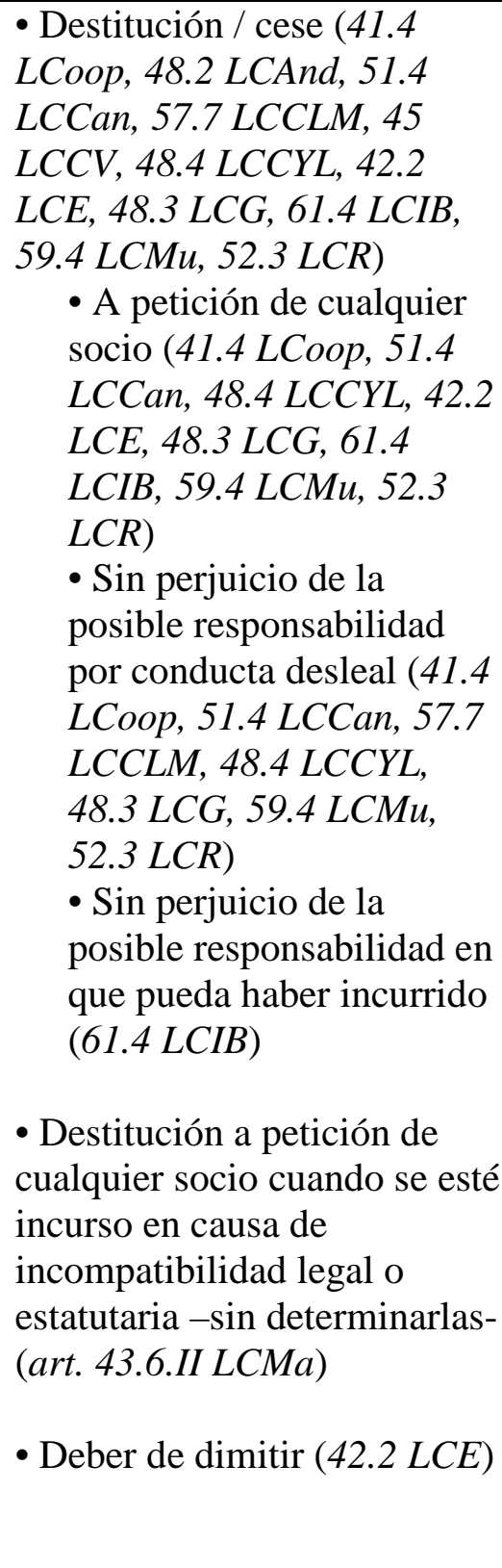 \\
\hline
\end{tabular}

g) Prohibición de voto o participación en toma de acuerdos

\begin{tabular}{|l|l|}
\hline CONTENIDO & $\begin{array}{l}\text { CONSECUENCIAS } \\
\text { INCUMPLIMIENTO }\end{array}$ \\
\hline $\begin{array}{l}\text { - Prohibición del socio implicado en un eventual conflicto de } \\
\text { intereses de tomar parte en la votación del correspondiente órgano } \\
\text {-incluido el órgano de administración- (52.2 LCAnd) }\end{array}$ & $\begin{array}{l}\text { No expresamente } \\
\text { previsto (acuerdo } \\
\text { anulable) }\end{array}$ \\
- Prohibición de voto de las personas afectadas en los supuestos de & \\
\hline
\end{tabular}

REVESCO Nº 120 - Primer Cuatrimestre 2016 - ISSN: 1885-8031 - www.ucm.es/info/revesco 
autocontratación -ver h- (42.1 LCoop, 43.3 LCAr, 52.1 LCCan, 49.1 LCG, 50.2 LCCat, 58 LCCLM, 49.1 LCCV, 49.1 LCCYL, 41.1 LCEx, 65.2 LCIB, 60.1 LCMu, 53.1 LCR)

- Prohibición de voto de las personas afectadas en los supuestos de ejercicio de acción de responsabilidad o de cese de los miembros de órganos sociales (33.3 LCCat)

- Prohibición de voto de las personas afectadas en el acuerdo en la asamblea general sobre dispensa de la prohibición de competencia del administrador (51.1 LCAs, 49.7 LCCLM)

- Prohibición de voto o de participación en toma de acuerdos relativos a los órganos de administración que versen sobre materias o asuntos en los que el administrador o sus familiares hasta el segundo grado inclusive puedan tener intereses personales, aunque no sean de naturaleza económica (114.4.l LCCV)

- Consideración de infracción administrativa muy grave (114.4.l LCCV): sanción económica e inhabilitación (118.1 $L C C V$ )

h) Prohibición de autocontratación

\begin{tabular}{|c|c|c|}
\hline CONTENIDO & DISPENSA & $\begin{array}{l}\text { CONSECUENCIAS } \\
\text { INCUMPLIMIENTO }\end{array}$ \\
\hline 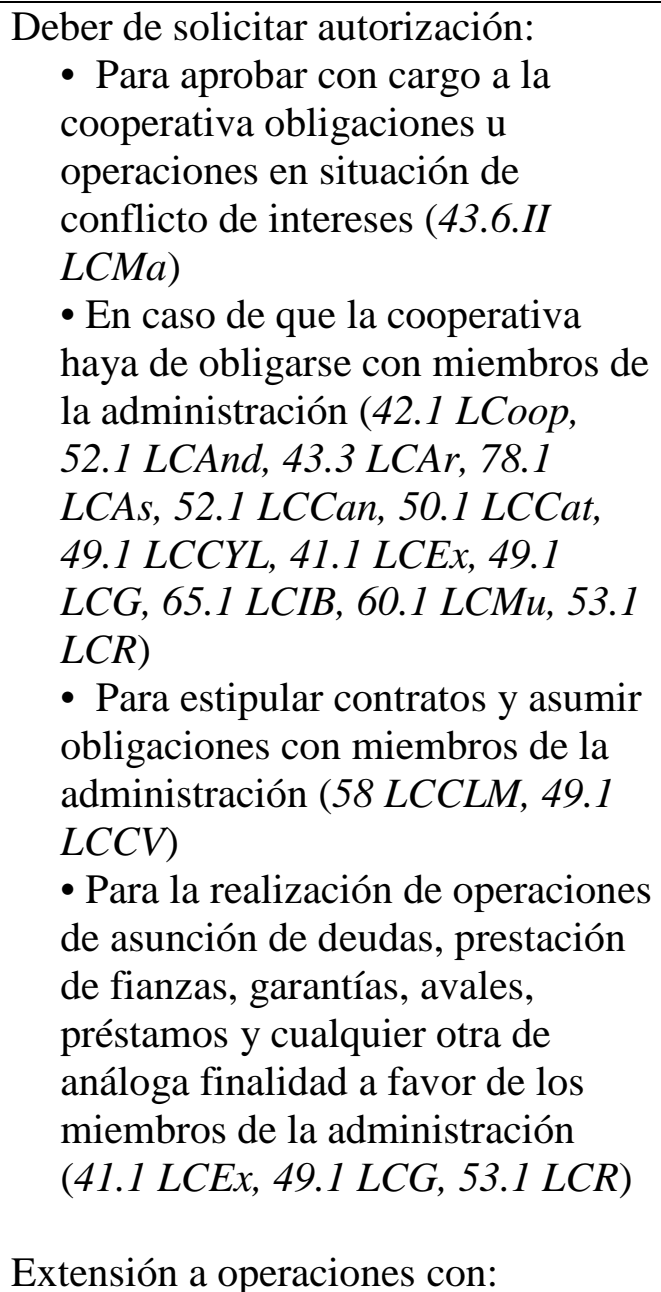 & $\begin{array}{l}\text { - Asamblea general } \\
\text { (42.1 LCoop, 43.3 } \\
\text { LCAr, 78.1 LCAs, } \\
52.1 \text { LCCan, 50.1 } \\
\text { LCCat, 49.1 LCCV, } \\
58 L C C L M, 49.1 \\
\text { LCCYL, 41.1 LCEx, } \\
\text { 48.1 LCG, 65.1 } \\
\text { LCIB, 43.6.II LCMa, } \\
60.1 \text { LCMu, 53.1 } \\
\text { LCR) } \\
\text { - Órgano de } \\
\text { administración (52.1 } \\
\text { LCAnd) } \\
\text { - Pero asamblea } \\
\text { general cuando la } \\
\text { administración de } \\
\text { la sociedad } \\
\text { cooperativa se } \\
\text { ejerza de manera } \\
\text { única o solidaria } \\
\text { (52.1 LCAnd) } \\
\text { - La autorización no } \\
\text { será necesaria: } \\
\text { • cuando se trate }\end{array}$ & 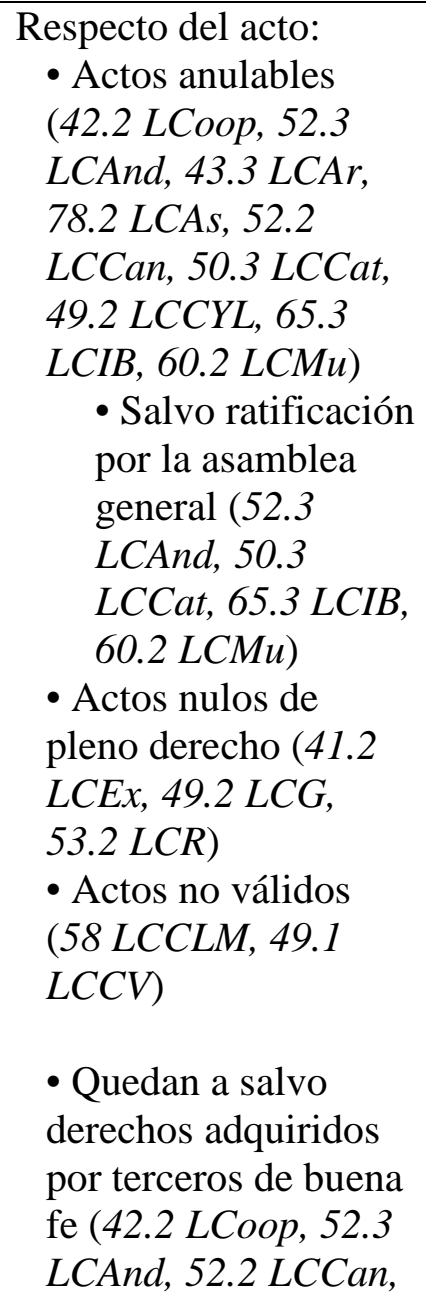 \\
\hline
\end{tabular}

REVESCO Nº 120 - Primer Cuatrimestre 2016 - ISSN: 1885-8031 - www.ucm.es/info/revesco 
- cónyuges (52.1 LCAnd, 41.1 LCEx, 65.1 LCIB, 60.1 LCMu)

- o parejas de hecho (52.1

LCAnd)

- o persona con quien convivan habitualmente (65.1 LCIB, 60.1 $L C M u)$

- o persona unida con análoga relación de afectividad (41.1 $L C E x$ )

- parientes hasta:

- $2^{\circ}$ grado de consanguinidad o afinidad (42.1 LCoop, $43.3 \mathrm{LCAr}$, 78.1 LCAs, 52.1 LCCan, 49.1 LCCYL, 41.1 LCEX, 49.1 LCG, 60.1 LCMu, 53.1 LCR)

- Tanto matrimonial como extramatrimonial (41.1 LCEx)

- $4^{\circ}$ grado de consanguinidad o $2^{\circ}$ de afinidad (52.1 LCAnd, 50.1 LCCat, 58 LCCLM, 49.1 LCCV) - 3er grado de consanguinidad o $2^{\circ}$ de afinidad (65.1 LCIB) de las relaciones

propias de la condición de socio (42.2 LCoop, , 52.1 LCAnd, 52.1 LCCan, 50.1 LCCat, 49.1 LCCYL, 41.1 LCEx, 48.1 LCG, 65.1 LCIB, 53.1 $L C R$ )

- Para la utilización de servicios cooperativizados (58 LCCLM, 49.1 $L C C V$ )

- Respecto del miembro vocal del consejo rector en representación de los trabajadores (41.1 LCEx)
50.3 LCCat, 58 LCCLM, 49.2 LCCV, 49.2 LCCYL, 41.2 LCEX, 49.2 LCG, 65.3 LCIB, 43.6.III LCMa, 60.2 LCMu, 53.2 LCR)

Respecto del administrador:

- Destitución a petición de cualquier socio (43.6.II LCMa)

- Cese y responsabilidad personal por los daños y perjuicios que se deriven para la cooperativa (41.2 LCEX, 49.2 LCG, 53.2 LCR)

i) Deber de secreto

\begin{tabular}{|c|c|}
\hline CONTENIDO & $\begin{array}{l}\text { CONSECUENCIAS } \\
\text { INCUMPLIMIENTO }\end{array}$ \\
\hline $\begin{array}{l}\text { - Deber de secreto (64.1 LCAs) } \\
\text { - Deber de guardar secreto sobre los datos que tengan carácter } \\
\text { confidencial aun después de haber cesado en sus funciones (50 } \\
L C A n d, 54.1 L C C a n, 63.3 L C C L M, 51.1 L C C Y L, 42.1 L C E x, 47.1 \\
L C E, 50.1 . I I L C G, 63.1 L C I B, 43.1 L C M a, 54.1 L C R) \\
\text { - Deber de guardar secreto profesional, aun después de cesar en sus } \\
\text { funciones ( } 44.1 L F C N)\end{array}$ & $\begin{array}{l}\text { No responsabilidad } \\
\text { específica } \\
\text { (responsabilidad } \\
\text { general) }\end{array}$ \\
\hline
\end{tabular}

j) Remuneración y compensación de gastos de los administradores

\begin{tabular}{|c|c|c|}
\hline CONTENIDO & CRITERIOS DE LA RETRIBUCIÓN & $\begin{array}{l}\text { FIJACIÓN DE } \\
\text { LA } \\
\text { RETRIBUCIÓN }\end{array}$ \\
\hline $\begin{array}{l}\text { - Posibilidad de pagar } \\
\text { retribuciones a los miembros del } \\
\text { órgano de administración ( } 40 \\
\text { LCoop, 49.I LCAnd, } 39.2 \text { LCAr, } \\
76 \text { LCAs, 53.I LCCan, } 43.2 \\
\text { LCCat, 60 LCCLM, 46.5 LCCV, }\end{array}$ & $\begin{array}{l}\text { - Competencia para fijar los criterios: } \\
\text { - Estatutos sociales (40 LCoop, } 76 \\
L C A s, 60 L C C L M, 46.5 L C C V, 58 \\
L C M u, 51 L C R \text { ) } \\
\text { - Estatutos sociales o asamblea } \\
\text { general (39.2 LCAr, } 43 L C E, 38.6\end{array}$ & $\begin{array}{l}\text { - Por asamblea } \\
\text { general ( } 40 \\
\text { LCoop, 28.f y } 49 \\
\text { LCAnd, } 76 \text { LCAs, } \\
\text { 32.2.b y } 53 \\
\text { LCCan, 43.1.a y }\end{array}$ \\
\hline
\end{tabular}

REVESCO N 120 - Primer Cuatrimestre 2016 - ISSN: 1885-8031 - www.ucm.es/info/revesco 


\begin{tabular}{|c|c|c|}
\hline $\begin{array}{l}50 \text { LCCYL, } 43 \text { LCE, 38.6 LCEx, } \\
47 \text { LCG, } 62 \text { LCIB, 43.5 LCMa, } \\
58 \text { LCMu, 51 LCR) } \\
\text { - Posibilidad limitada a: } \\
\text { - Los miembros no socios }\end{array}$ & $\begin{array}{l}\text { LCEx, } 47 \text { LCG, } 43.5 \text { LCMa) } \\
\text { - Asamblea general (28.f LCAnd, } 53 \\
\text { LCCan, 29.1.b LCCat, } 50 \text { LCCYL, } 62 \\
\text { LCIB) } \\
\text { - A instancia del órgano de } \\
\text { administración (49 LCAnd) } \\
\text { - Criterios específicos: } \\
\text { - No pueden fijarse en función de los } \\
\text { resultados económicos del ejercicio } \\
\text { social (39.2 LCAr, 53.I LCCan, } 50 \\
L C C Y L, 38.6 L C E x) \\
\text { - Si se abonasen con cargo a } \\
\text { excedentes disponibles no podrán } \\
\text { impedir la cobertura de los Fondos } \\
\text { obligatorios o estatutarios, ni la } \\
\text { posibilidad de retornos (60 LCCLM, } \\
43.5 L C M a) \\
\text { - Siempre retribuciones moderadas y } \\
\text { proporcionadas a las prestaciones } \\
\text { efectivas de los consejeros y al } \\
\text { volumen económico de la cooperativa } \\
\text { (60 LCCLM, } 43.5 \text { LCMa) }\end{array}$ & $\begin{array}{l}\text { - Además, } \\
\text { recogerse en } \\
\text { memoria anual } \\
\text { (40 LCoop, } 76 \\
L C A s, 60 \\
L C C L M, 62 \text { LCIB, } \\
58 L C M u, 51 \\
L C R \text { ) } \\
\text { - Los estatutos } \\
\text { fijarán a qué } \\
\text { órgano le } \\
\text { corresponde fijar } \\
\text { la cuantía de la } \\
\text { compensación por } \\
\text { gastos y perjuicios } \\
\text { (43.3 LCCat) } \\
\text { - Fijación por la } \\
\text { asamblea general } \\
\text { (46.5 LCCV) }\end{array}$ \\
\hline
\end{tabular}

\section{UNA VISIÓN GENERAL: ELEMENTOS DESTACABLES}

Las tablas presentadas en las páginas anteriores, que resumen las concreciones del deber de lealtad para los socios y administradores de las cooperativas de forma comparada y teniendo en cuenta la totalidad de las leyes de cooperativas vigentes en el Estado español, ofrecen una valiosa información para la aplicación, interpretación y, en su caso, actualización 
de la legislación cooperativa de forma completa y comparada, o elaboración de estatutos sociales o códigos de conducta.

No obstante, además de ofrecer de forma sistematizada toda esta información para ser empleada a tales efectos, o ser tomada como base para posteriores trabajos de desarrollo, del análisis genérico y conjunto del contenido de la información expuesta pueden extraerse algunos elementos interesantes, que presentan el panorama general sobre el estado del desarrollo de la legislación cooperativa en materia del deber de lealtad.

Por un lado, si reparamos al deber de lealtad de los socios, se han detectado hasta 12 concreciones diferentes de éste en la legislación cooperativa. Si bien es cierto que no todas ellas se encuentran en la totalidad de las leyes de cooperativas, algunas previsiones son generalizadas: la previsión de la prohibición de alcanzar acuerdos que lesionen, en beneficio de uno o varios socios, o de terceros, los intereses de la sociedad cooperativa (todas las leyes); la prohibición de voto en caso de conflicto de intereses (si bien por lo general lo hacen de forma muy poco concreta, en 14 de las leyes de cooperativas encontramos referencia a este aspecto, debiendo añadir las previsiones relativas a la presidencia o secretaría de la asamblea general en caso de conflicto de intereses en 6 casos); la prohibición de competencia (todas las leyes, con diferentes formulaciones); o del deber de secreto (todas las leyes). A las anteriores deben añadirse otras como la prohibición de tener una voluntad de beneficiarse indebidamente con la baja obligatoria -que ha de relacionarse con el art. 224 CCo- (9 leyes), la prohibición de pertenecer a una cooperativa a título de empresario, contratista, capitalista y otro análogo, respecto de aquélla o de los socios como tales (6 leyes), la prohibición de prevalerse de la condición de socio para realizar actividades especulativas o lícitas (5 leyes), la prohibición de realizar actividades que puedan perjudicar a los intereses de la cooperativa (4 leyes), la prohibición de descrédito a la cooperativa o de realizar manifestaciones que puedan perjudicar los intereses de ésta (4 leyes), la prohibición de tener un fin y un objeto social contrarios a los principios cooperativos y/o el objeto social de la cooperativa (3 leyes), el deber de respeto a los órganos de gobierno (1 ley), o la previsión general del deber de lealtad hacia la cooperativa (1 ley).

Entre las anteriores encontramos tanto las señaladas concreciones del deber de lealtad del socio en las sociedades de capital, así como las indicadas para las sociedades colectivas y comanditarias, superándolas ampliamente. 
Nótese además que la legislación cooperativa recoge otra serie de previsiones más o menos relacionadas con el deber de lealtad, no incluidas en las tablas anteriores, que en parte derivan también del elemento personalista de las cooperativas $\mathrm{y}$, en especial, de la participación de los socios en la actividad cooperativizada, como son el deber de permanencia durante un periodo mínimo, el plazo de preaviso preceptivo para causar baja, el deber de participar en la actividad cooperativizada respetando la participación mínima estatutariamente prevista, así como el deber de cumplir con sus obligaciones económicas, la obligación de asistir a las reuniones de los órganos sociales de los que sea parte, el deber de cumplir los acuerdos sociales, etc ${ }^{10}$.

Por lo que respecta a los administradores, la legislación cooperativa recoge específicamente el deber de lealtad de los administradores (13 leyes), la prohibición de competencia y su dispensa (expresamente en 16 leyes, correspondiendo por lo general la autorización a la asamblea general, debiendo añadirse que en 2 leyes se prevé la prohibición de desempeñar cargos en otras sociedades no filiales con igual o análogo género de actividad u objeto), la prohibición de ocupar altos cargos o ser personal al servicio de la Administración con funciones relacionadas con las actividades de las cooperativas (16 leyes), la prohibición de autocontratación salvo autorización (15 leyes), siendo también bastante generalizada la prohibición de voto en caso de conflicto de intereses, por lo general en relación con la autorización para la autocontratación (13 leyes en este supuesto específico, a las que ha de añadirse 1 caso de prohibición general de voto en los casos de conflicto de intereses, 1 en los supuestos de ejercicio de la acción de responsabilidad o de cese, y 2 en los acuerdos sobre dispensa de la prohibición de competencia), o el deber de secreto (12 leyes). La posibilidad de remunerar a los administradores se prevé en 16 de las leyes, si bien sólo en 6 de ellas se establece algún criterio legal para su determinación. Otras concreciones legales de este deber son la prohibición de adoptar acuerdos que lesionen, en beneficio de uno o varios socios o terceros los intereses de la sociedad (8 leyes, si bien puede considerarse aplicable en el resto), la prohibición de tener un interés opuesto al de la sociedad (6 leyes), así como la prohibición de extralimitarse en sus facultades ( 2 leyes). Resulta destacable asimismo el tratamiento que en la LCCV se otorga a la prohibición de competencia y a la prohibición de voto, cuyo incumplimiento podría considerarse infracción administrativa muy grave.

\footnotetext{
${ }^{10}$ Entre otros, ver: Morillas y Feliú (2002) y Gadea (2001).
} 
Es decir, a pesar de que la legislación cooperativa contiene diversas concreciones del deber de lealtad (se han agrupado en 10 deberes), lo cierto es que su desarrollo legal es considerablemente menor que en el caso de las sociedades de capital. Ha de valorarse que algunas de las concreciones de este deber para las sociedades de capital no se contienen en ninguna ley de cooperativas, como la libertad de criterio, el deber de información, el deber genérico de evitar situaciones de conflicto, la prohibición de utilizar el nombre de la sociedad y de invocar la condición de administrador para la realización de operaciones por cuenta propia o de personas vinculadas, la prohibición de aprovechar oportunidades de negocio, la prohibición de hacer uso de los activos sociales con fines privados, o la prohibición de obtener ventajas o remuneraciones de terceros. Por otro lado, muchos de los deberes que sí se recogen, no se encuentran en la totalidad de leyes de cooperativas, y en las que sí se hallan normalmente contienen una redacción muy genérica (y todo ello sin entrar a valorar las diferencias en la redacción de los preceptos y sus consecuencias prácticas).

Finalmente, al mismo tiempo, ha de subrayarse que la legislación cooperativa toma en cuenta, especialmente a la hora de regular la prohibición de autocontratación de los administradores, particularidades propias de estas sociedades, como es el hecho de que la condición de administrador recaerá normalmente sobre los propios socios, que llevan a cabo la actividad cooperativizada, lo que explica la excepción expresa en algunas leyes de las relaciones propias de la condición de socio o para la utilización de servicios cooperativizados.

\section{CONSIDERACIONES PRELIMINARES}

Por lo tanto, si hemos de extraer una valoración o conclusión general de los datos anteriores, podríamos señalar el mayor desarrollo del deber de lealtad de los socios en la legislación cooperativa, frente a un desarrollo notablemente inferior de la regulación del deber de lealtad de los administradores. Además, la situación varía ostensiblemente dependiendo de la Ley de cooperativas de que se trate, siendo una materia no homogeneizada.

La explicación a la especial atención que presta el legislador cooperativo al deber de lealtad de los socios hemos de encontrarla en que, a pesar de que las cooperativas suelen clasificarse como sociedades de estructura corporativa, mantienen un notable carácter personalista, dada la importancia de las características personales de los socios, y, ante todo, su directa participación en la actividad de la cooperativa, que queda lejos de limitarse a las aportaciones al capital. 
En este punto, no hay que perder de vista que la causa del contrato social de las cooperativas sería precisamente el interés común de los socios cooperativistas, esto es, la satisfacción de sus necesidades y aspiraciones económicas y sociales, mediante la participación en la actividad cooperativizada (Morillas y Feliú, 2002; Vargas, 2006). Es por este motivo por el que cobra singular importancia la norma general de la legislación cooperativa de prohibición de competencia por parte de los socios.

Así, podría decirse que la legislación cooperativa es coherente en este punto, pudiendo incluso calificarse de pedagógica. No obstante, deben realizarse al menos dos apreciaciones en este punto, que también se señalarán en cuanto al deber de lealtad de los administradores: por un lado, los diferentes legisladores cooperativos deberían revisar sus textos legales a efectos de mejorar la regulación de esta cuestión, teniendo en cuenta para ello el análisis comparado, y, al menos, corregir las imprecisiones o contradicciones existentes en aquéllos; por otro lado, como se expone más adelante, es de suma relevancia recordar que el deber de lealtad de los socios deriva del contrato de sociedad, y que los socios deben actuar en todo caso en interés de ésta, estén o no legalmente recogidas las conductas en que se concreta tal deber.

Por otro lado, en cuanto al menor desarrollo legal del deber de lealtad de los administradores -aunque la legislación cooperativa ha ido acercándose progresivamente a la legislación de las sociedades de capital, en particular en aspectos como la regulación del órgano de administración (Suso, 1996 -se refiere a la LCE, si bien es la línea general que han seguido las distintas leyes de cooperativas)-, éste ha sido interpretado como una menor exigencia en estas sociedades, hablándose por lo tanto de una asimetría del deber de diligencia y lealtad en las cooperativas y en las sociedades de capital. Asimismo, se ha defendido un menor deber de desarrollar estos deberes para las cooperativas, teniendo en cuenta sus actividades y funcionamiento ${ }^{11}$. Sin embargo, lo anterior ha de matizarse.

Por un lado, hay que tener en cuenta que en las cooperativas, junto al interés de los socios y de otros interesados o stakeholders, los principios cooperativos quedan incluidos en el interés de la sociedad (Morillas, 2002; Coutinho, 2002), lo que podría suponer una cierta ampliación del deber de lealtad y diligencia (Gallego, 2003).

\footnotetext{
${ }^{11}$ Ver Gallego (2009: 102-103).
} 
Por otro lado, como se ha subrayado, el deber de lealtad es inherente tanto a los socios como a los administradores, puesto que, en último término, deriva del deber de buena fe, que es siempre de obligado cumplimiento. Como se señalaba, no hay que olvidar que la cooperativa tiene un interés propio derivado del fin común establecido en el contrato social, que vincula a los socios y a los administradores, cuya labor es precisamente gestionar ese interés. De este modo, la falta de previsión del deber de lealtad (o de sus concreciones) no implicaría que éste no exista, sino simplemente que no está desarrollado o completado, y en todo caso persistirá la obligación de anteponer los intereses de la sociedad a los propios ${ }^{12}$. La previsión general del deber de lealtad cumpliría así una función de cláusula general residual para enjuiciar las conductas de los socios y de los administradores (Oriol, 2013).

Por ello, debe entenderse que en todo caso deben cumplirse los deberes que son parte del "cabal contenido" del deber de lealtad, entre los que podrían incluirse, el deber de no explotar ilegítimamente y de modo oportunista los beneficios y ventajas que correspondan a la cooperativa, comunicar las situaciones de conflicto de intereses, abstenerse en la toma de decisiones relacionadas con el conflicto, evitar usar el nombre de la cooperativa para realizar operaciones por cuenta propia y aprovechar oportunidades de negocio cuyo conocimiento se derive de su condición de gestor y en las que esté interesada la sociedad, difundir opiniones que desacrediten a la sociedad, etc. (Grimaldos, 2013, en referencia a los adminstradores; Coutinho, 2002).

No obstante, a pesar de lo anterior, parece conveniente, en beneficio de la cooperativa, de los socios, de los administradores y de terceros, aclarar estos aspectos en la legislación cooperativa. El desarrollo legal de los deberes que derivan del deber de lealtad (y de su incumplimiento), además de tener un importante efecto pedagógico, dotaría a la cooperativa y a las distintas personas afectadas de mejores instrumentos para proteger sus lícitos intereses ante los constantes conflictos de intereses que surgen entre la sociedad y sus socios y administradores, aumentando asimismo la seguridad jurídica. Por ello, a la vista de las apreciaciones realizadas, parece conveniente defender un mayor desarrollo legal de estos aspectos, siempre teniendo en cuenta y respetando las particularidades propias de las

\footnotetext{
${ }^{12}$ Grimaldos, (2013) señala en este sentido la STS de 4 de octubre de 2011; Ribas, (2010) en cuanto a los socios, Irakulis (2013).
} 
cooperativas y las relaciones que ésta mantiene con sus socios y administradores ${ }^{13}$. Todo ello, sin perjuicio del ámbito de la autorregulación de la sociedad, mediante sus estatutos o reglamento interno, o la posible aprobación de códigos de conducta $^{14}$.

\section{BIBLIOGRAFÍA}

ALFONSO, R. y SÁNCHEZ RUIZ, M. (2007) Aspectos generales sobre el buen gobierno de las cooperativas y de los grupos cooperativos, Revista de Derecho Mercantil, No 266, pp. 1051-1086.

ALONSO ESPINOSA, F. J. (1996) La posición jurídica del socio en la Ley 2/1995, de 23 de marzo, de sociedades de responsabilidad limitada (aspectos generales). En: IGLESIAS, J. L., Estudios jurídicos en homenaje al profesor Aurelio Menéndez, Vol. II, Madrid: Civitas, pp. 1443-1462.

ARROYO, I. (2002) Reflexiones en torno al interés social. En: Derecho de Sociedades. Libro homenaje a Fernando Sánchez Calero, Vol. II. Madrid: McGraw Hill, pp. 1845-1858.

COUTINHO, J. A. (2002) Interés social y deber de lealtad de los socios, Revista de Derecho de Sociedades, $\mathrm{N}^{\mathrm{o}} 19$, pp. 39-56.

GADEA, E. (2001) Derecho de las cooperativas. Análisis de la Ley 4/1993, de 24 de junio, de cooperativas del País Vasco (2a ed.), Bilbao: Universidad de Deusto.

GALLEGO, L. P. (2013) Notas en torno al régimen jurídico de responsabilidad civil de los administradores de cooperativas, CIRIEC-España, Revista Jurídica de Economía Social y Cooperativa, № 20, pp. 83-114.

DAVIES, P. L. y WORTHINGTON, S. (2012) Gower and Davies' principles of modern company law ( $9^{\mathrm{a}} \mathrm{ed}$.). Londres: Sweet \& Maxwell.

FERNÁNDEZ DE LA GÁNDARA, L. (2010) Derecho de sociedades. Tomos I y II. Valencia: Tirant lo Blanch.

\footnotetext{
${ }^{13}$ Así se pronuncia también en general la doctrina existente al respecto (por ejemplo, en cuanto al régimen de retribución de los administradores, Gadea, 2001; ver asimismo sobre estas cuestiones Puentes; Velasco y Vilar, 2009).

${ }^{14}$ Lo que también puede resultar conveniente atendiendo a las particularidades organizativas de las cooperativas y el principio de auto-organización (en este punto, ver Alfonso y Sánchez Ruiz, 2007, que defienden el desarrollo de las normas de buen gobierno en las cooperativas, aun sin trasladar automáticamente las normas pensadas en un principio para sociedades cotizadas, en especial mediante normas estatutarias, respetando las particularidades y la auto-organización de las cooperativas).

Un ejemplo de código de buen gobierno destacable es el realizado por Konfekoop y Erkide (Kooperatiben gobernu onaren kodea - Código de buen gobierno de las cooperativas), disponible en www.erkide.coop/erkide/publicaciones/detalle.php?Npublica=1307618462\&id=es.
}

REVESCO No 120 - Primer Cuatrimestre 2016 - ISSN: 1885-8031 - www.ucm.es/info/revesco 
GRIMALDOS, M. I. (2013) La responsabilidad civil de los administradores de entidades de economía social. En: GÓMEZ, M. F.; PARDO, M. M. Economía Social y Derecho. Problemas jurídicos actuales de las empresas de economía social. Granada: Comares, pp. 67-93.

IRAKULIS, N. (2013) Conflictos de interés del socio. Cese del administrador nombrado por accionista competidor. Madrid: Marcial Pons.

MORILLAS, M. J. (2002) Las normas de conducta de los administradores de las sociedades de capital. Madrid: La Ley.

MORILLAS, M. J. y FELIÚ, M. I. (2002) Curso de cooperativas (2 ${ }^{\mathrm{a}}$ ed.). Madrid: Tecnos.

ORIOL, J. (2013) Los deberes y la responsabilidad de los administradores. En: ROJO, A.; BELTRÁN, E. La responsabilidad de los administradores de las sociedades mercantiles

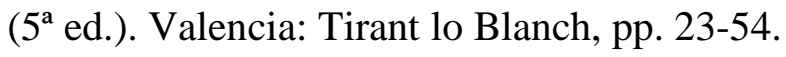

PAZ-ARES, C. (2013) La anomalía de la retribución externa de los administradores: hechos nuevos y reglas viejas, Revista de Derecho Mercantil, No 290, pp. 85-140.

PUENTES, R.; VELASCO, M. M. y VILAR, J. (2009) El buen gobierno corporativo en las sociedades cooperativas, REVESCO. Revista de Estudios Cooperativos, № 98, pp. 118140.

RIBAS, V. (2010) El deber de lealtad del administrador de sociedades, Madrid: La Ley.

RIBAS, V. (2012) Deberes de los administradores en la Ley de Sociedades de Capital, Revista de Derecho de Sociedades, No 38, pp. 73-153.

SUSO, J. M. (1996) La confluencia del derecho de sociedades mercantiles en el régimen de los órganos sociales de la Ley de Cooperativas de Euskadi de 1993. En: IGLESIAS, J. L., Estudios jurídicos en homenaje al profesor Aurelio Menéndez, Vol. II, Madrid: Civitas, pp. 2509-2542.

VARGAS, C (2006) La actividad cooperativizada y las relaciones de la cooperativa con sus socios y con terceros, Cizur Menor: Thomson Aranzadi (Revista de Derecho de Sociedades, monografía $\mathrm{N}^{\mathrm{o}} 27$ ). 